\title{
TWO-DIMENSIONAL ANALOGY OF THE KOROUS INEQUALITY
}

\author{
Branislav FTOREK, PAVOl OrŠANSKÝ AND HELENA ŠAMAJOVÁ
}

Abstract. J. Korous reached an important and interesting result for general orthogonal polynomials in one variable. In the paper we generalize this result for orthogonal polynomials in two variables. The boundedness of two families of orthonormal polynomials associated with an arbitrary weight function $w(x, y)$ and its extension $W(x, y)=w(x, y) h(x, y)$, where $h(x, y)$ is a function satisfying certain conditions, is investigated.

Mathematics subject classification (2010): 33C45, 33C50, 33D50. boundedness.

Keywords and phrases: Weight function, Korous theorem, orthogonal polynomials in two variables,

\section{REFERENCES}

[1] J. Dunham, Fourier Series and Orthogonal Polynomials, Dover Publications, Dover Ed edition 2004.

[2] B. FTOREK AND M. MARČOKOVÁ, Markov type polynomial inequality for some generalized Hermite weight, Tatra Mt. Math. Publ. 49 (2011), 111-118.

[3] B. FTOREK AND P. ORŠANSKÝ, Korous type inequalities for orthogonal polynomials in two variables, Tatra Mt. Math. Publ. 58 (2014), 1-12.

[4] D. JACKSON, Formal properties of orthogonal polynomials in two variables, Duke Math. Journ. 2 (1936), 423-434.

[5] T. H. Koornwinder, Orthogonal Polynomials in Two Variables which are Eigenfunctions of Two Algebraically Independent Partial Differential Operators I, II, Indag. Math. 36 (1974), no. 1, 48-66.

[6] T. H. Koornwinder, Orthogonal Polynomials in Two Variables which are Eigenfunctions of Two Algebraically Independent Partial Differential Operators III, IV, Indag. Math. 36 (1974), no. 4, $357-$ 381.

[7] J. Korous, The Development of Functions of One Real Variable in the Certain Series of Orthogonal Polynomials, Rozpravy II. tř́́dy České akademie věd v Praze 40 (1938), 1-12. (In Czech)

[8] H. L. Krall And I. M. Sheffer, Orthogonal Polynomials in Two Variables, Ann. Mathem. pura ed appl. 76 (1967), no. 4, 325-376.

[9] E. LEVIN AND D. S. LUBINSKY, Orthogonal polynomials with exponential weights $x^{2 \rho} e^{-2 Q(x)}$ on $[0, d)$, J. Approx. Theory 134 (2005), 199-256.

[10] M. MARČOKOVÁ, Equiconvergence of two Fourier series, J. Approx. Theory 80 (2) (1995), 151-163.

[11] P. NevaI, Géza Freud, orthogonal polynomials and Christoffel functions, J. Approx. Theory 48 (1) (1986), 3-167.

[12] P. K. Sujetin, Orthogonal Polynomials in Two Variables, Anal. Methods Spec. Funct., Vol. 3, Gordon and Breach Sci. Publ., Amsterdam, 1999.

[13] Pawel J. SZabŁowsKi, On affinity relating two positive measures and the connection coefficients between polynomials orthogonalized by these measures, J. Math. Comput. 219 (2013), No. 12, 6768 6776, MR3027843.

[14] PAWEL J. SZABŁows Ki, Expansions of one density via polynomials orthogonal with respect to the other, J. Math. Anal. Appl. 383 (2011), No. 1, 35-54, MR2812716, http://arxiv.org/abs/ 1011.1492.

[15] G. SzEGÖ, Orthogonal Polynomials, Nauka, Moscow 1962. (In Russian) 